\title{
Predictors of complete miscarriage after expectant management or misoprostol treatment of non-viable early pregnancy in women with vaginal bleeding
}

\author{
Anna Fernlund ${ }^{1,2}$ (1) $\cdot$ Ligita Jokubkiene ${ }^{1,2} \cdot$ Povilas Sladkevicius $^{1,2}$ (i) $\cdot$ Lil Valentin $^{1,2}$ (1)
}

Received: 6 February 2020 / Accepted: 25 June 2020 / Published online: 7 July 2020

(c) The Author(s) 2020

\begin{abstract}
Purpose To identify predictors of complete miscarriage after expectant management or misoprostol treatment of non-viable early pregnancy in women with vaginal bleeding.

Methods This was a planned secondary analysis of data from a published randomized controlled trial comparing expectant management with vaginal single dose of $800 \mu \mathrm{g}$ misoprostol treatment of women with embryonic or anembryonic miscarriage. Predefined variables - serum-progesterone, serum- $\beta$-human chorionic gonadotropin, parity, previous vaginal deliveries, gestational age, clinical symptoms (bleeding and pain), mean diameter and shape of the gestational sac, crown-rump-length, type of miscarriage, and presence of blood flow in the intervillous space-were tested as predictors of treatment success (no gestational sac in the uterine cavity and maximum anterior-posterior intracavitary diameter was $\leq 15 \mathrm{~mm}$ as measured with transvaginal ultrasound on a sagittal view) in univariable and multivariable logistic regression.

Results Variables from 174 women (83 expectant management versus 91 misoprostol) were analyzed for prediction of complete miscarriage at $\leq 17$ days. In patients managed expectantly, the rate of complete miscarriage was $62.7 \%$ (32/51) in embryonic miscarriages versus $37.5 \%(12 / 32)$ in anembryonic miscarriages $(P=0.02)$. In multivariable logistic regression, the likelihood of success increased with increasing gestational age, increasing crown-rump-length and decreasing gestational sac diameter. Misoprostol treatment was successful in 80.0\% (73/91). No variable predicted success of misoprostol treatment. Conclusions Complete miscarriage after expectant management is significantly more likely in embryonic miscarriage than in anembryonic miscarriage. Gestational age, crown-rump-length, and gestational sac diameter are independent predictors of success of expectant management. Predictors of treatment success may help counselling women with early miscarriage.
\end{abstract}

Keywords First-trimester pregnancy $\cdot$ Misoprostol $\cdot$ Pregnancy complications $\cdot$ Logistic models prediction $\cdot$ Miscarriage

\section{Introduction}

Early miscarriage occurs in $10-15 \%$ of clinically recognized pregnancies [1-3]. Expectant or medical management are alternatives to surgical evacuation [4-6]. Randomized trials comparing medical treatment, most often misoprostol, with expectant management or placebo show substantial

Anna Fernlund

anna.fernlund@skane.se

1 Department of Obstetrics and Gynecology, Skåne University Hospital, Jan Waldenströms gata 47, 20502 Malmö, SE, Sweden

2 Department of Clinical Sciences Malmö, Lund University, Lund, Sweden variation in success rates defined as complete miscarriage without surgical intervention [4-10]. The discrepancies are explained by differences in types of miscarriage included, symptomatology, definition of complete miscarriage and treatment success, and dose regimens of drugs. First-trimester miscarriages can be classified on ultrasound as (1) anembryonic, i.e., a gestational sac that is empty or with minimal embryonic debris without cardiac activity [11], (2) embryonic, i.e., a gestational sac with a visible embryo or fetus without cardiac pulsations [11], or as (3) incomplete miscarriage, i.e., no visible gestational sac but ultrasound signs of retained products of conception [12]. Incomplete miscarriages usually resolve spontaneously within a few weeks [12]. Expectant management of miscarriages with a retained gestational sac is less likely to be successful within a few weeks, especially in women with no vaginal bleeding 
[13]. Most studies investigating possible predictors of treatment success of medical treatment or expectant management include both incomplete miscarriages and embryonic or anembryonic miscarriages and/or both patients with and without vaginal bleeding [13-32]. This makes results difficult to generalize.

The aim of this work is to identify predictors of success of expectant management or misoprostol treatment in a welldefined group of patients, i.e., patients with embryonic or anembryonic miscarriage reporting vaginal bleeding.

\section{Material and methods}

This is a planned secondary analysis of prospectively collected data in a published randomized controlled trial comparing expectant management with vaginal single dose $800 \mu \mathrm{g}$ misoprostol treatment of embryonic and anembryonic first-trimester miscarriage [6] (ClinicalTrials.gov ID: NCT01033903). The regional ethical review board, Lund University, Sweden, approved the trial (Dnr 83/2008), which was carried out in accordance with the code of ethics of the Declaration of Helsinki. The primary trial outcome was complete miscarriage $\leq 10$ weeks. Secondary outcomes were complete miscarriage $\leq 17, \leq 24$ and $\leq 31$ days. Complete miscarriage was defined as no gestational sac in the uterine cavity and maximum anterior-posterior diameter of the intracavitary contents $\leq 15 \mathrm{~mm}$ as measured with transvaginal ultrasound on a sagittal view. Trial details (including a CONSORT flow chart) have been published [6] and are briefly outlined below.

Women consulting the gynecological emergency clinic of Skåne University Hospital, Malmö, Sweden and reporting vaginal bleeding in early pregnancy were eligible for inclusion if hemodynamically stable. Women with heavy bleeding needing urgent surgical evacuation of the uterine cavity, as judged clinically, were not eligible. Inclusion criteria were: $\geq 18$ years old, understanding written and spoken Swedish, hemoglobin concentration $>80 \mathrm{~g} / \mathrm{L}$, no contraindications to misoprostol treatment, fulfilling ultrasound criteria of anembryonic or embryonic miscarriage [11], and fetal crown-rump-length $\leq 33 \mathrm{~mm}$. Because of new recommendations [33-35] our ultrasound criteria of non-viability were changed in 2014. Before 2014 the criteria were (1) intracavitary gestational sac with a diameter (mean of three orthogonal diameters) of $>16 \mathrm{~mm}$ with no embryonic pole [36] or (2) intracavitary gestational sac with an embryo with crown-rump-length $\geq 5 \mathrm{~mm}$ without cardiac pulsations [36], or (3) if the above criteria were not fulfilled, intracavitary gestational sac with or without an embryo showing no significant development at a repeat scan after 7 days [36]. After April 2014 our non-viability criteria were: (1) intracavitary gestational sac with a mean diameter $\geq 25 \mathrm{~mm}$ with no embryonic pole, or (2) intracavitary gestational sac with an embryo with crown-rump-length $\geq 7 \mathrm{~mm}$ without cardiac pulsations, or (3) if the above criteria were not fulfilled, no significant development at a repeat scan after 7 days $[33,34$, $37,38]$. Women with incomplete miscarriage were not eligible. Women giving written consent were randomized into two parallel groups in an open-label 1:1 ratio to misoprostol treatment or expectant management. All patients were managed as outpatients.

The patients were examined clinically and with transvaginal ultrasound in the lithotomy position on the day of randomization. The trial clinician estimated bleeding and pain at speculum and clinical examination and placed $800 \mu \mathrm{g}$ misoprostol in the posterior vaginal fornix of the patients allocated to medical treatment. The first follow-up was after 10 days. Subsequent follow-up visits were scheduled every 7 days until the miscarriage was complete (definition, see above). The patient was then discharged with no planned follow-up visits. If complete evacuation was not achieved on day 31 , dilatation and evacuation was recommended. However, the participants could ask for dilatation and evacuation at any time for any reason during the trial.

At inclusion, information on demographic background data was collected from the woman and documented in research forms, and blood was drawn for analysis of hemoglobin, $\beta$-human chorionic gonadotropin ( $\beta$-hCG), progesterone and blood type. $\mathrm{hCG}+\beta$ was measured with a sandwich immunoassay on a Cobas ${ }^{\circledR}$ instrument; Intact hCG + the $\beta$-subunit assay (Roche Diagnostics, Mannheim, Germany). Progesterone was measured with a competitive immunoassay on a Cobas ${ }^{\circledR}$ instrument; Progesterone III assay (Roche Diagnostics, Mannheim, Germany). On every follow-up visit clinical examination and transvaginal ultrasound were performed. Results were prospectively entered into research forms.

The ultrasound machine used was a Sequoia 512 ultrasound system (Siemens Medical Solutions Inc., Ultrasound Division, Mountain View, CA, USA) with a 4-8 MHz transducer. The shape of the gestational sac was assessed, the sac diameter and the crown-rump-length (if an embryo/fetus was present) were measured. The miscarriage was classified as embryonic or anembryonic. Assessment of blood flow in the presumed intervillous space was first made by looking for 
Table 1 Association between predefined possible predictors and success of expectant management of embryonic and anembryonic miscarriage $\leq 10$ days (univariable logistic regression analysis); $n=85$

\begin{tabular}{|c|c|c|c|c|}
\hline Variables tested as possible predictors & Success $(n=39)$ & Failure $(n=46)$ & $P$ value $^{\mathrm{a}}$ & Odds ratio $(95 \% \mathrm{CI})$ \\
\hline \multicolumn{5}{|l|}{ Biochemical variables } \\
\hline s-beta-human chorionic gonadotropin (IU/L) ${ }^{\mathrm{b}}$ & & 2 missing & 0.01 & $0.956(0.919-0.996)^{\mathrm{c}}$ \\
\hline Mean & $9387.6 \pm 7690.1$ & $17,744.8 \pm 19,865.8$ & & \\
\hline Median & $7650.0(107-26,585)$ & $9328.5(1006-80,317)$ & & \\
\hline $\mathrm{s}$-Progesterone $(\mathrm{nmol} / \mathrm{L})^{\mathrm{b}}$ & & 1 missing & 0.011 & $0.971(0.942-1.000)$ \\
\hline Mean & 18.9 & 32.3 & & \\
\hline Median & $18.0(3-41)$ & $19.0(4-190)$ & & \\
\hline \multicolumn{5}{|l|}{ Clinical variables } \\
\hline Gestational age according to last menstrual period & 2 missing & 3 missing & 0.053 & $1.040(0.998-1.083)$ \\
\hline Mean & $77.8 \pm 11.1$ & $72.9 \pm 11.7$ & & \\
\hline Median & $76.0(60-104)$ & $73.0(42-94)$ & & \\
\hline \multicolumn{5}{|l|}{ Vaginal delivery } \\
\hline Yes & $20(51.3)$ & $28(60.9)$ & 0.374 & $0.677(0.285-1.604)$ \\
\hline No & $19(48.7)$ & $18(39.1)$ & & \\
\hline \multicolumn{5}{|l|}{ Parity } \\
\hline Parous & $24(61.3)$ & $29(63.0)$ & 0.887 & $0.938(0.389-2.262)$ \\
\hline Nulliparous & $15(38.5)$ & $17(37.0)$ & & \\
\hline \multicolumn{5}{|l|}{ Bleeding at inclusion ${ }^{\mathrm{d}}$} \\
\hline Moderate/heavy & $8(20.5)$ & $5(10.9)$ & 0.218 & $2.116(0.631-7.102)$ \\
\hline None/mild & $31(79.5)$ & $41(89.1)$ & & \\
\hline \multicolumn{5}{|l|}{ Pain at inclusion } \\
\hline Yes & $12(30.8)$ & $12(26.1)$ & 0.633 & $1.259(0.489-3.244)$ \\
\hline No & $27(69.2)$ & $34(73.9)$ & & \\
\hline \multicolumn{5}{|l|}{ Ultrasound variables } \\
\hline Gestational sac & & & 0.624 & $0.788(0.303-2.047)$ \\
\hline Not round/oval & $10(25.6)$ & $14(30.4)$ & & \\
\hline Round/oval & $29(74.4)$ & $32(69.6)$ & & \\
\hline Gestational sac diameter $(\mathrm{mm})^{\mathrm{e}}$ & & 1 missing & 0.448 & $0.981(0.933-1.031)$ \\
\hline Mean & 23.3 & 24.5 & & \\
\hline Median & $21.0(4.7-49.0)$ & $23.3(10.7-41.0)$ & & \\
\hline Crown-rump-length (mm) & & & 0.008 & $1.102(1.020-1.191)$ \\
\hline Mean & $7.5 \pm 7.3$ & $4.0 \pm 4.9$ & & \\
\hline Median & $5.5(0.0-26.0)$ & $3.1(0.0-17.0)$ & & \\
\hline \multicolumn{5}{|l|}{ Miscarriage type on ultrasound } \\
\hline Embryonic & $28(71.8)$ & $24(52.2)$ & 0.063 & $2.333(0.943-5.774)$ \\
\hline Anembryonic & $11(28.2)$ & $22(47.8)$ & & \\
\hline Crown-rump-length if embryonic miscarriage (mm) & $n=28$ & $n=24$ & 0.06 & $1.105(0.988-1.235)$ \\
\hline Mean & $10.5 \pm 6.6$ & $7.6 \pm 4.3$ & & \\
\hline Median & $9.5(3.0-26.0)$ & $5.5(3.0-17.0)$ & & \\
\hline \multicolumn{5}{|l|}{ Blood flow in presumed intervillous space according to } \\
\hline Grey-scale ultrasound & & & 0.288 & $0.398(0.069-2.299)$ \\
\hline Yes & $35(89.7)$ & $44(95.7)$ & & \\
\hline No & $4(10.4)$ & $2(4.3)$ & & \\
\hline Color Doppler ultrasound & & 1 missing & 0.109 & $0.327(0.078-1.363)$ \\
\hline Yes & $32(82.1)$ & $42(93.3)$ & & \\
\hline No & $7(17.9)$ & $3(6.7)$ & & \\
\hline Spectral Doppler ultrasound (arterial blood flow) & 4 missing & 5 missing & 0.619 & $0.786(0.304-2.032)$ \\
\hline Yes & $22(62.9)$ & $27(65.9)$ & & \\
\hline No & $13(37.1)$ & $14(34.1)$ & & \\
\hline
\end{tabular}


Table 1 (continued)

Data are presented as $n(\%)$, mean \pm SD or median (range)

$C I$ confidence interval

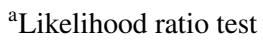

${ }^{b}$ After mid May 2013 beta-human chorionic gonadotropin and progesterone were analyzed in plasma not in serum, reference intervals are not affected

${ }^{\mathrm{c}}$ Odds ratio is calculated for units of 1000

${ }^{\mathrm{d}}$ Bleeding as judged by the trial physician at speculum examination —all women reported vaginal bleeding

${ }^{\mathrm{e}}$ Mean of three orthogonal diameters

flickering areas within the chorion on grey-scale imaging. The color Doppler function was then switched on starting with standardized settings (space-time S2; edge zero; persistence two; color map V2; gate two; filter three; frequency $7 \mathrm{MHz}$; color Doppler gain 50; pulse repetition frequency corresponding to blood flow velocity $2.1 \mathrm{~cm} / \mathrm{s}$ ) which were adjusted to maximize detection of slow velocity blood flow without artifacts. A Doppler gate was placed where color Doppler signals were seen inside the chorion. By adjusting the position of the probe, arterial Doppler shift signals inside the chorion were searched for as previously described [39, 40]. Presence of blood flow in the presumed intervillous space as assessed on grey scale and color Doppler and of arterial Doppler shift signals in the presumed intervillous space was noted.

Women not showing up on a scheduled visit were included in this secondary analysis only if on a later visit the miscarriage was incomplete; the miscarriage was then classified as incomplete also on the missed visit. Women with a complete miscarriage on the first visit after the missed one were not included in the analysis, because we do not know, if the miscarriage was complete also on the missed visit.

We considered the following variables to be possibly related to treatment outcome and explored their ability to predict complete miscarriage $\leq 10$ days and $\leq 17$ days: serum/plasma levels of progesterone (nmol/L) and $\beta$-hCG (IU/L) at inclusion, gestational age (days) according to the last menstrual period (LMP), previous vaginal delivery (yes/no), parity (yes/no), bleeding at inclusion (moderate or heavy versus mild or none as assessed by the trial physician at speculum examination), pain at inclusion (yes/no), shape of the gestational sac (round or oval versus else), mean gestational sac diameter $(\mathrm{mm})$, crown-rump-length $(\mathrm{mm})$, type of miscarriage (embryonic or anembryonic), presence of blood flow in the presumed intervillous space according to grey scale and color Doppler ultrasound (yes/no), and presence of arterial Doppler shift signals in the presumed intervillous space (yes/no).

Statistical analysis was performed using SPSS Statistics, version 21 (IBM Corp., Armonk, NY, USA). It was done separately for the misoprostol group and the expectantly managed group and separately for treatment success $\leq 10$ days and $\leq 17$ days. The relation between the predefined predictor variables and treatment success was tested for statistical significance using univariable logistic regression with the likelihood ratio test. Two-tailed $P$ values $<0.05$ were considered statistically significant. Multivariable logistic regression was used to elucidate which variables were independently associated with treatment success and for building models to predict complete miscarriage. Because crown-rump-length and miscarriage type are related (in anembryonic miscarriages the crown-rump-length is zero), only one of these variables was included in the same multivariable analysis. We used different approaches for model building. In one, we included all predetermined variables (with a minimum of five individuals in each cell of a fourfield table) in multivariable backward step-wise logistic regression analysis. In another, we started with including only variables with a $P$ value $<0.20$ in univariable analysis, and then we tested to add variables that we found clinically relevant.

Individual data for each patient were inserted into the regression models to calculate the probability of complete miscarriage for each patient and to plot receiver-operating characteristics curves. The area under the receiver-operating characteristic curve (AUC) and its $95 \%$ confidence interval (CI) were calculated. If the lower limit of the CI was $>0.5$ the model was considered to have discriminatory ability. The larger the AUC the better the discriminative ability.

\section{Results}

Between September 2008 and December 2015189 women were recruited into the trial. Ninety-five women were allocated to expectant management and 94 to misoprostol treatment. Twenty-one women (expectant group: 11; misoprostol group: 10) were recruited after the new ultrasound criteria of non-viability were adopted. After exclusions, our planned secondary analysis included 177 women (expectant group: 85; misoprostol group: 92). The reasons for exclusion were: 
Table 2 Association between predefined possible predictors and success of expectant management of embryonic and anembryonic miscarriage $\leq 17$ days (univariable logistic regression analysis); $n=83$

\begin{tabular}{|c|c|c|c|c|}
\hline Variables tested as possible predictors & Success $(n=44)$ & Failure $(n=39)$ & $P$ value $^{\mathrm{a}}$ & Odds ratio $(95 \% \mathrm{CI})$ \\
\hline \multicolumn{5}{|l|}{ Biochemical variables } \\
\hline s-beta-human chorionic gonadotropin (IU/L) ${ }^{\mathrm{b}}$ & & 2 missing & 0.01 & $0.958(0.922-0.995)^{\mathrm{c}}$ \\
\hline Mean & $9530.6 \pm 7483.3$ & $18,128.3 \pm 21,019.9$ & & \\
\hline Median & $8308.0(107-26,585)$ & $7990.0(1006-80,317)$ & & \\
\hline $\mathrm{s}$-Progesterone $(\mathrm{nmol} / \mathrm{L})^{\mathrm{b}}$ & & 1 missing & 0.003 & $0.965(0.936-0.995)$ \\
\hline Mean & $18.5 \pm 10.6$ & $34.6 \pm 38.2$ & & \\
\hline Median & $18.0(3-41)$ & $20.5(4-190)$ & & \\
\hline \multicolumn{5}{|l|}{ Clinical variables } \\
\hline Gestational age according to last menstrual period (days) & 2 missing & 3 missing & 0.04 & $1.042(1.000-1.086)$ \\
\hline Mean & $77.8 \pm 10.7$ & $72.4 \pm 12.4$ & & \\
\hline Median & $78.0(60-104)$ & $72.0(42-94)$ & & \\
\hline \multicolumn{5}{|l|}{ Vaginal delivery } \\
\hline Yes & $25(56.8)$ & $23(59.0)$ & 0.843 & $0.915(0.382-2.195)$ \\
\hline No & $19(43.2)$ & $16(41.0)$ & & \\
\hline \multicolumn{5}{|l|}{ Parity } \\
\hline Yes & $29(65.9)$ & $24(61.5)$ & 0.679 & $1.208(0.493-2.963)$ \\
\hline No & $15(34.1)$ & $15(38.5)$ & & \\
\hline \multicolumn{5}{|l|}{ Bleeding at inclusion ${ }^{\mathrm{d}}$} \\
\hline Moderate/heavy & $10(22.7)$ & $3(7.7)$ & 0.053 & $3.529(0.894-13.927)^{\mathrm{e}}$ \\
\hline None/mild & $34(77.3)$ & $36(92.3)$ & & \\
\hline \multicolumn{5}{|l|}{ Pain at inclusion } \\
\hline Yes & $13(29.5)$ & $11(28.2)$ & 0.893 & $1.067(0.412-2.765)$ \\
\hline No & $31(70.5)$ & $28(71.8)$ & & \\
\hline \multicolumn{5}{|l|}{ Ultrasound variables } \\
\hline Gestational sac & & & 0.925 & $0.955(0.365-2.499)$ \\
\hline Not round/oval & $12(27.3)$ & $11(28.2)$ & & \\
\hline Round/oval & $32(72.7)$ & $28(71.8)$ & & \\
\hline Gestational sac diameter $(\mathrm{mm})^{\mathrm{f}}$ & & 1 missing & 0.967 & $0.999(0.950-1.050)$ \\
\hline Mean & $24.1 \pm 9.5$ & $24.1 \pm 7.9$ & & \\
\hline Median & $21.4(4.7-49.0)$ & $23.2(10.7-41.0)$ & & \\
\hline \multicolumn{5}{|l|}{ Crown-rump-length (mm) } \\
\hline Mean & $7.5 \pm 7.0$ & $3.6 \pm 4.9$ & 0.004 & $1.119(1.028-1.218)$ \\
\hline Median & $5.6(0.0-26.0)$ & $0.0(0.0-17.0)$ & & \\
\hline \multicolumn{5}{|l|}{ Miscarriage type on ultrasound } \\
\hline Embryonic & $32(72.7)$ & $19(48.7)$ & 0.024 & $2.807(1.126-6.998)$ \\
\hline Anembryonic & $12(27.3)$ & $20(51.3)$ & & \\
\hline Crown-rump-length if embryonic miscarriage (mm) & $n=32$ & $n=19$ & 0.069 & $1.109(0.981-1.254)$ \\
\hline Mean & $10.3 \pm 6.2$ & $7.4 \pm 4.6$ & & \\
\hline Median & $9.5(3.0-26.0)$ & $5.3(3.0-17.0)$ & & \\
\hline \multicolumn{5}{|l|}{ Blood flow in presumed intervillous space according to } \\
\hline Grey-scale ultrasound & & & 0.105 & $0.205(0.023-1.840)$ \\
\hline Yes & $39(88.6)$ & $38(97.4)$ & & \\
\hline No & $5(11.4)$ & $1(2.6)$ & & \\
\hline Color Doppler ultrasound & & 1 missing & 0.008 & $0.105(0.013-0.873)$ \\
\hline Yes & $35(79.5)$ & $37(94.9)$ & & \\
\hline No & $9(20.5)$ & $1(2.6)$ & & \\
\hline Spectral Doppler ultrasound (arterial blood flow) & 4 missing & 4 missing & 0.125 & $0.468(0.175-1.252)$ \\
\hline Yes & $23(57.5)$ & $25(71.4)$ & & \\
\hline No & $17(42.5)$ & $10(28.6)$ & & \\
\hline
\end{tabular}


Table 2 (continued)

Data are presented as $n(\%)$, mean $\pm \mathrm{SD}$, median (range)

$C I$ confidence interval

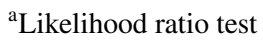

${ }^{\mathrm{b}}$ After mid May 2013 beta-human chorionic gonadotropin and progesterone were analyzed in plasma and not in serum, reference intervals are not affected

${ }^{\mathrm{c}}$ Odds ratio is calculated for units of 1000

${ }^{\mathrm{d}}$ Bleeding as judged by the trial physician at speculum examination-all women reported vaginal bleeding

${ }^{\mathrm{e}}$ We consider this result unreliable, because only three patients in the failure group had heavy or moderate bleeding, the unreliable result is also reflected in the odds ratio

${ }^{\mathrm{f}}$ Mean of three orthogonal diameters

withdrawal of consent (expectant group, $n=2$ ), not fulfilling inclusion criteria (expectant group, $n=3$ ), undergoing dilatation and evacuation before first follow-up at 10 days (expectant group, $n=5$; misoprostol group, $n=2$ ). For the analysis regarding prediction of complete miscarriage $\leq 17$ days another three patients were excluded due to dilatation and evacuation on patient's request (expectant group $n=1$ ) or missed follow-up visit (expectant group $n=1$, misoprostol group $n=1)$, the numbers analyzed for this outcome being 83 (expectant group) and 91 (misoprostol group).

Expectant management was successful $\leq 10$ days in $45.8 \%$ (39/85) of the patients and $\leq 17$ days in $53.0 \%$ (44/83). Variables associated with success of expectant management in univariable and multivariable analyses are shown in Tables 1, 2, 3, 4 and 5. Treatment success was more common in embryonic than anembryonic miscarriages: complete miscarriage $\leq 10$ days $53.8 \%$ (28/52) versus $33.0 \%$ (11/33) $(P=0.06)$, complete miscarriage $\leq 17$ days $62.7 \%(32 / 51)$ versus $37.5 \%(12 / 32)(P=0.02)$. In multivariable analyses, the following variables were independently associated with treatment success: gestational age according to LMP (the higher the more likely successful treatment), mean gestational sac diameter (the smaller the more likely successful treatment) and crown-rump-length (the larger the more likely successful treatment). When we replaced crownrump-length with type of miscarriage in the multivariable model, the odds of treatment success were approximately six times higher in embryonic than anembryonic miscarriages (Table 3). When s- $\beta$-hCG and s-progesterone were tested as predictors in multivariable analysis, either s-progesterone or s- $\beta$-hCG (not both) and crown-rump-length or miscarriage type were independently associated with complete miscarriage (Tables 4 and 5). The AUCs of the models ranged from 0.71 to 0.77 .

In embryonic miscarriages, the higher the gestational age according to LMP, the larger the crown-rump-length and the smaller the mean gestational sac diameter the higher the likelihood of complete miscarriage $\leq 10$ and $\leq 17$ days (Table 6); and the lower the s-progesterone or s- $\beta$-hCG and the longer the crown-rump-length the higher the success rate
(Table 7). The AUCs of the models ranged from 0.80 to 0.84 . No variable was statistically significantly associated with complete miscarriage of anembryonic miscarriages when using expectant management (details available from the authors on request).

Misoprostol treatment was successful $\leq 10$ days in $67 \%$ (62/92) of patients and $\leq 17$ days in $80 \%$ (73/91). No variable predicted success of misoprostol treatment either in embryonic or anembryonic miscarriages. (Details available from the authors on request).

\section{Comments}

In patients managed expectantly the likelihood of spontaneous complete miscarriage $\leq 10$ or $\leq 17$ days was twice as high in embryonic as in anembryonic miscarriages. The likelihood of complete miscarriage increased with increasing gestational age according to LMP, increasing crownrump-length and decreasing gestational sac diameter; and the larger the crown-rump-length and the lower the s- $\beta$-hCG or s-progesterone level the higher the likelihood of treatment success. No variable predicted treatment outcome in the misoprostol group.

The strength of our study is the well-defined study population. We included only embryonic and anembryonic miscarriages and only women reporting vaginal bleeding. Our results are generalizable to such women. It is a limitation that we changed our definitions of non-viable pregnancy at the end of the recruitment period because of new research results and guidelines [33-35, 37, 38, 41-43]. However, it is unlikely that this had any major impact on our results. Our definition of successful treatment, also used by others [7, $8,19,27,44]$, may also be criticized [45-48]. Absence of a gestational sac and/or cessation of vaginal bleeding may be better definitions [49]. It is a weakness that our prediction models have not been validated in a new study sample. In our trial, we did not find any association between presence of blood flow or pulsatile flow in the intervillous space and treatment success. However, we did not make any attempts 


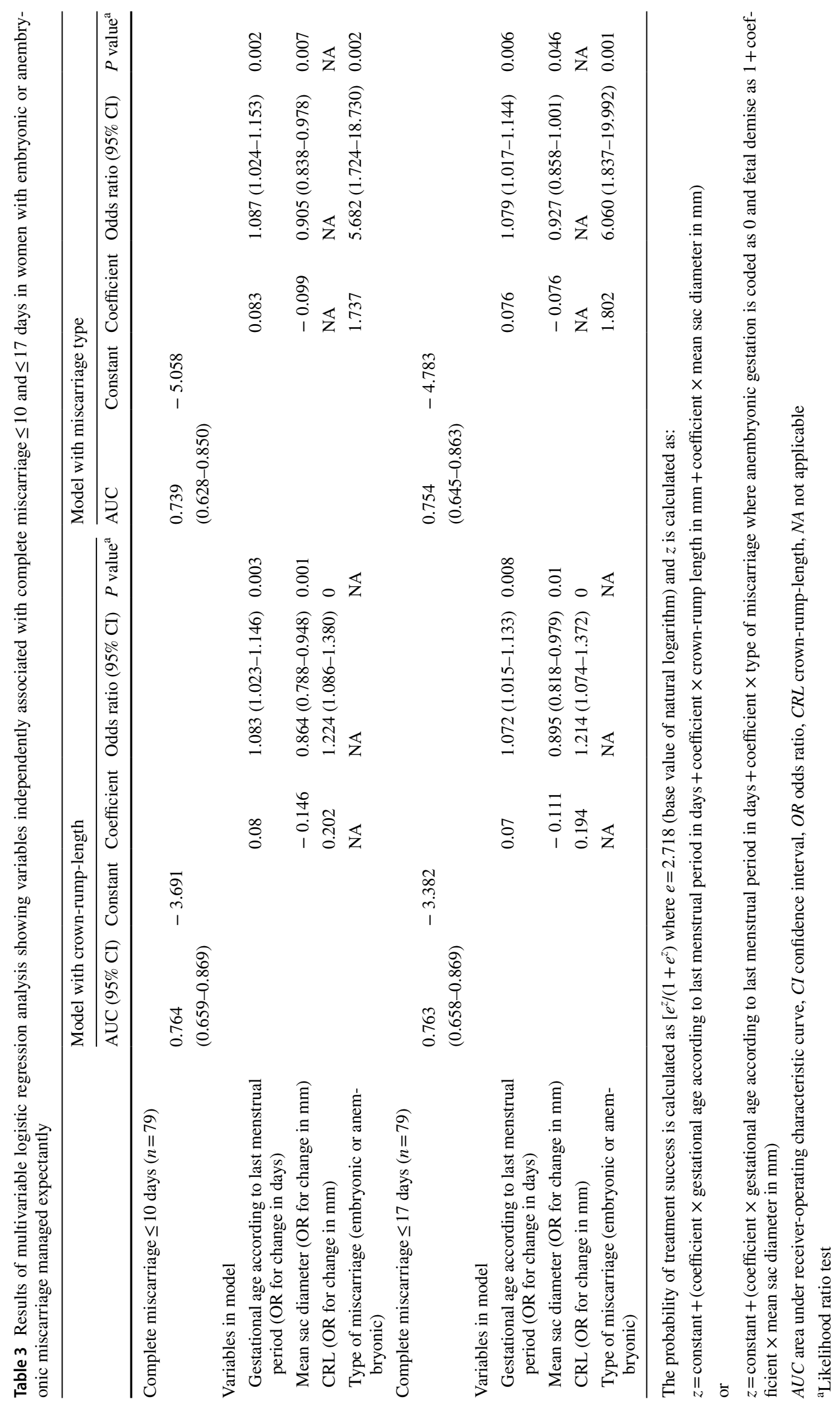




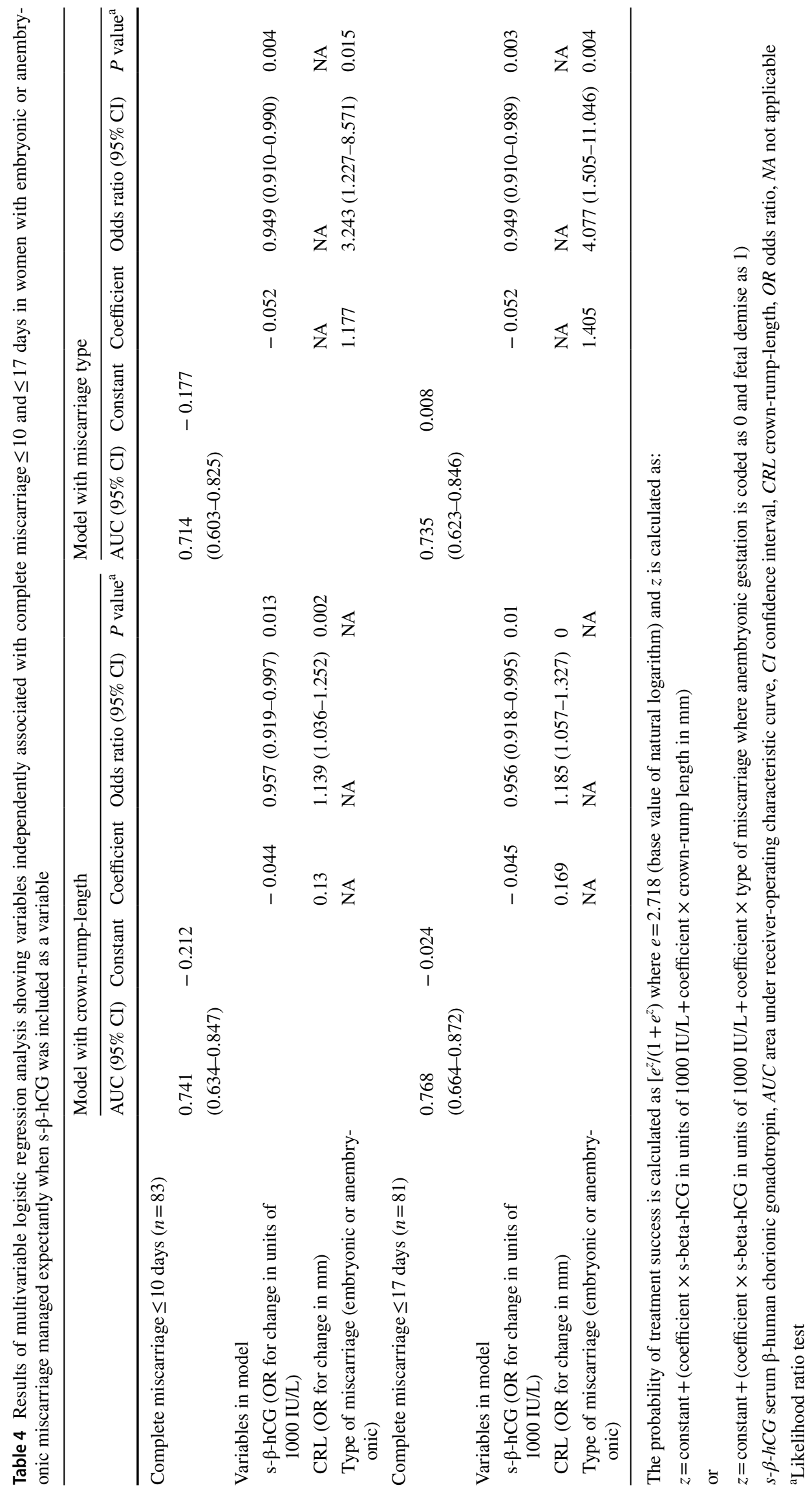




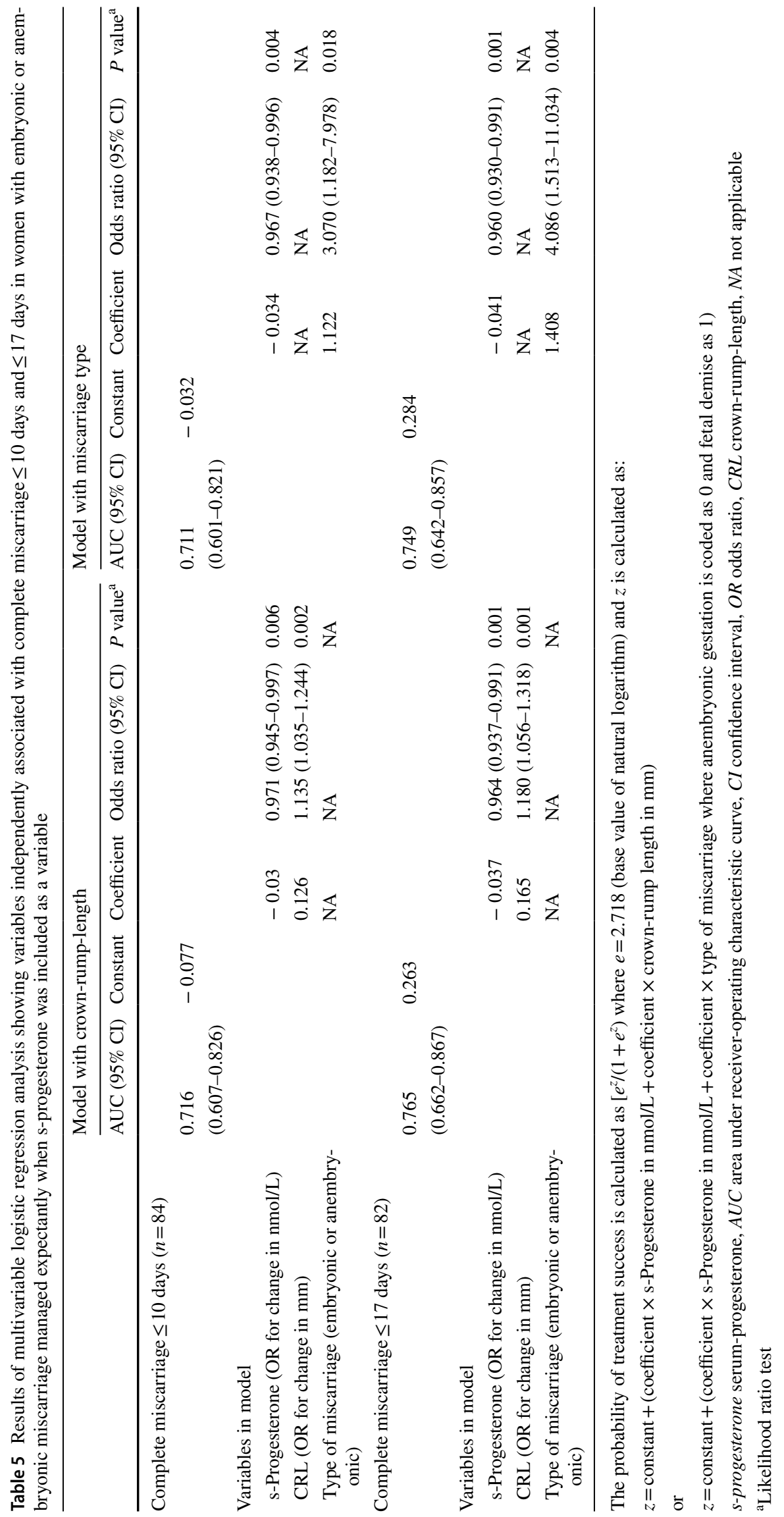


Table 6 Results of multivariable logistic regression analysis showing variables independently associated with complete miscarriage $\leq 10$ days and $\leq 17$ days in women with embryonic miscarriage managed expectantly

\begin{tabular}{|c|c|c|c|c|c|}
\hline & AUC $(95 \%$ CI $)$ & Constant & Coefficient & Odds ratio $(95 \%)$ & $P$ value \\
\hline \multicolumn{6}{|l|}{ Complete miscarriage $\leq 10$ days $(n=48)$} \\
\hline & $\begin{array}{l}0.843 \\
(0.732-0.954)\end{array}$ & -5.397 & & & \\
\hline \multicolumn{6}{|l|}{ Variables in model } \\
\hline $\begin{array}{l}\text { Gestational age according to last menstrual } \\
\text { period (OR for change in days) }\end{array}$ & & & 0.131 & $1.140(1.024-1.268)$ & 0.005 \\
\hline Mean sac diameter (OR for change in $\mathrm{mm}$ ) & & & -0.226 & $0.797(0.693-0.918)$ & 0 \\
\hline CRL (OR for change in mm) & & & 0.222 & $1.249(1.036-1.505)$ & 0.007 \\
\hline \multicolumn{6}{|l|}{ Complete miscarriage $\leq 17$ days $(n=47)$} \\
\hline & $\begin{array}{l}0.802 \\
(0.657-0.948)\end{array}$ & -5.609 & & & \\
\hline \multicolumn{6}{|l|}{ Variables in model } \\
\hline $\begin{array}{l}\text { Gestational age according to last menstrual } \\
\text { period (OR for change in days) }\end{array}$ & & & 0.129 & $1.137(1.022-1.266)$ & 0.006 \\
\hline Mean sac diameter (OR for change in $\mathrm{mm}$ ) & & & -0.177 & $0.838(0.733-0.958)$ & 0.002 \\
\hline CRL (OR for change in mm) & & & 0.17 & $1.186(0.987-1.424)$ & 0.043 \\
\hline
\end{tabular}

The probability of treatment success is calculated as $\left[e^{z} /\left(1+e^{z}\right)\right.$ where $e=2.718$ (base value of natural logarithm) and $z$ is calculated as:

$z=$ constant + (coefficient $\times$ gestational age according to last menstrual period in days + coefficient $\times$ mean sac diameter in mm + coefficient $\times$ crown-rump length in $\mathrm{mm}$ )

$A U C$ area under receiver-operating characteristic curve, $C I$ confidence interval, $O R$ odds ratio, $C R L$ crown-rump-length

${ }^{\mathrm{a}}$ Likelihood ratio test

to quantify blood flow, for example using three-dimensional ultrasound and calculating vascular indices. This may be seen as a limitation.

The results of other studies exploring possible predictors of complete miscarriage with expectant management are very heterogenous (Table 8) [13-22, 25, 30]. This is probably explained by differences in study populations (types of miscarriage, symptomatology), definitions of complete miscarriage and treatment success, and variables tested as predictors. However, more than one study reported that the lower the s- $\beta$-hCG and s-progesterone values the higher the likelihood of success of expectant management [16, 18, $19,21]$ and that success rate is higher in incomplete miscarriages than in embryonic or anembryonic miscarriages [15-17]. Only two studies are reasonably similar to ours with regard to inclusion criteria and definition of treatment success $[18,21]$. Schwärzler et al. found that pulsatile flow in the presumed intervillous space was a predictor of successful treatment [21]. We could not confirm this, perhaps because examination of blood flow in the intervillous space in early pregnancy requires skill, carefulness and time. Therefore, it is unlikely to be useful in busy emergency departments or early pregnancy units. Memtsa et al. reported that the older the patient and the lower the s-progesterone level the higher the likelihood of complete miscarriage $<7$ days [18]. We did not test patient age as a predictor, because we found it unlikely to be related to the time to complete evacuation of the uterine cavity.

Our results seem plausible from a pathophysiological perspective. Higher concentrations of s- $\beta$-hCG and s-progesterone probably reflect better functioning corpus luteum and trophoblast and are compatible with earlier stages of miscarriage explaining longer time to complete miscarriage. The relation between gestational age according to LMP, crownrump-length and gestational sac diameter may reflect the time since the embryo died. The apoptotic process may be faster for the gestational sac than for the embryo. This could be an explanation for a smaller gestational sac being a predictor of treatment success. Long time between embryonic death and start of bleeding may also indicate resistance to expulsion. In some anembryonic miscarriages, the absence of an embryo might be explained by the embryo having been resorbed after having been dead for a long time.

The likely reason why we did not find any predictor of successful misoprostol treatment is that misoprostol is very effective in most patients. Results of other studies investigating predictors of successful misoprostol treatment are extremely variable (Table 8) [23, 24, 26-29, 31, 32] and no study is directly comparable to ours. The variable results are 


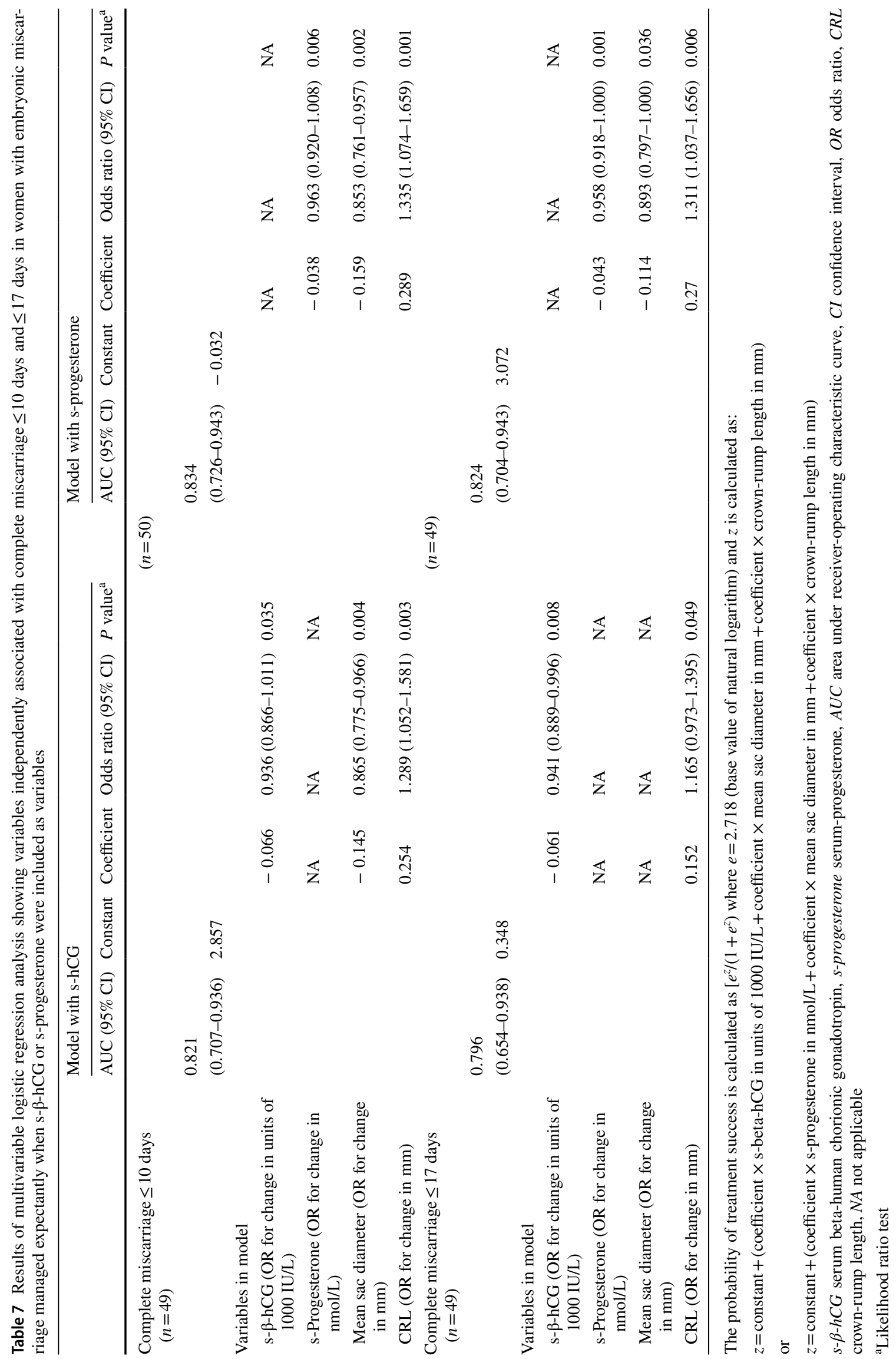




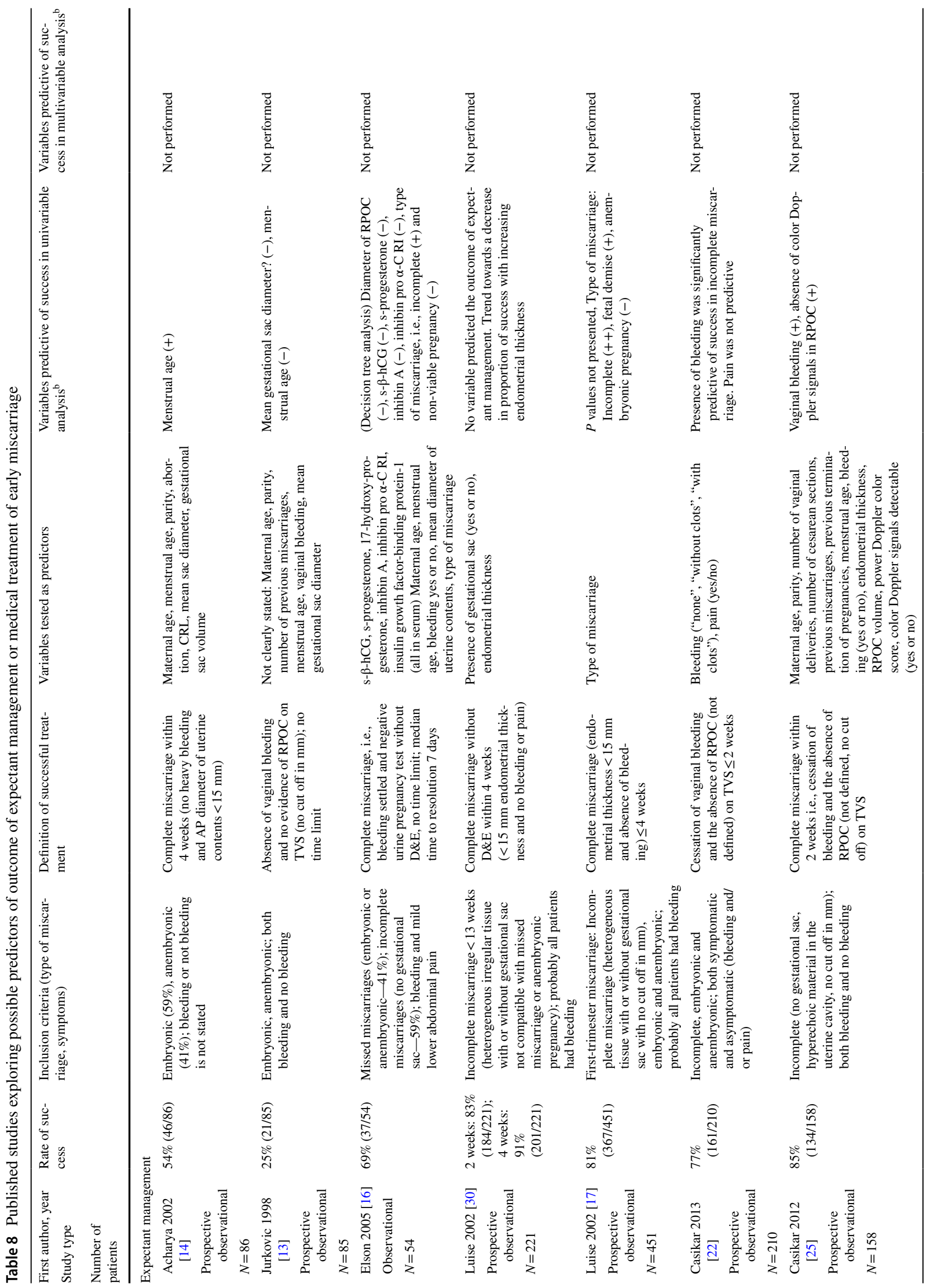




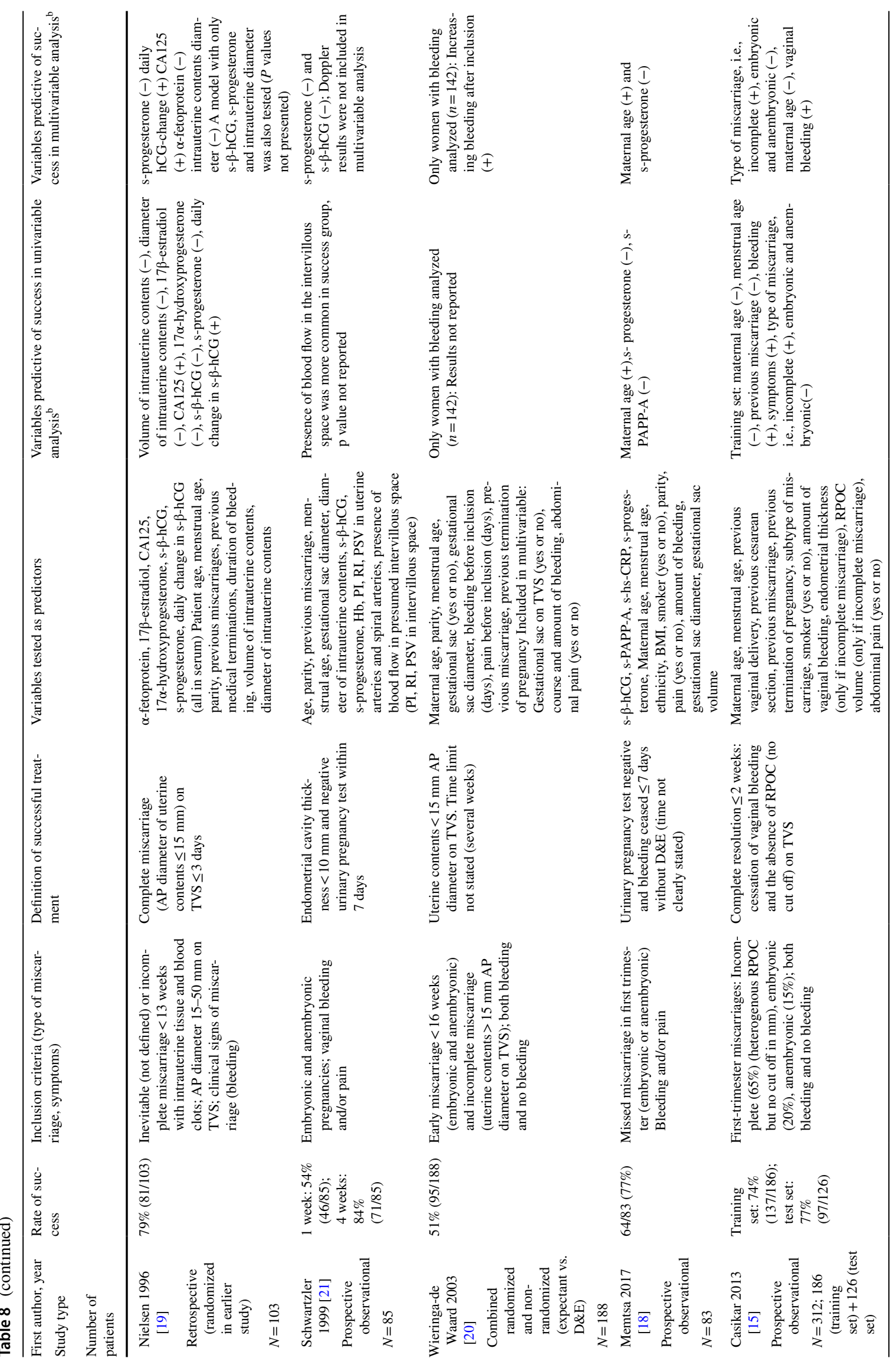




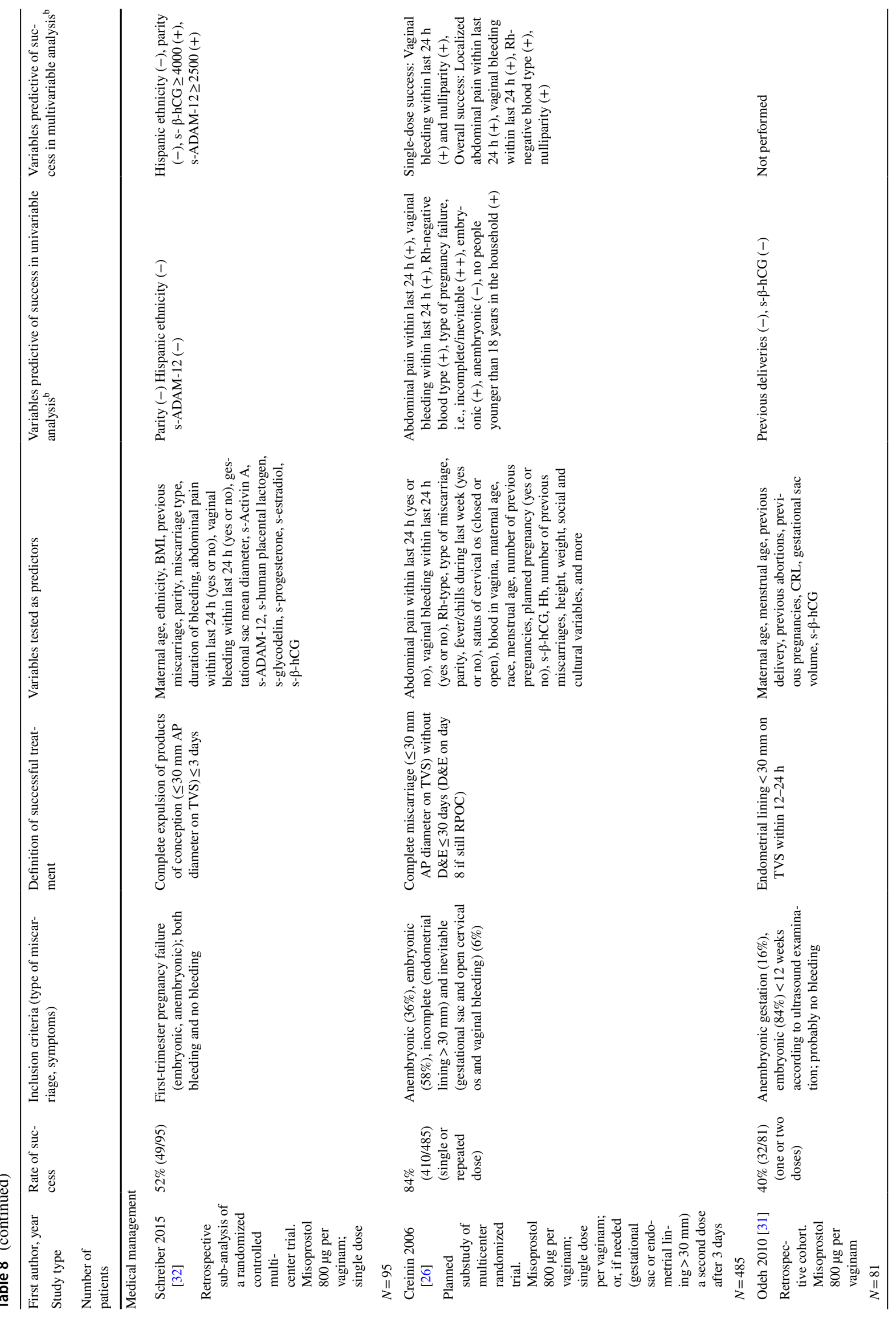




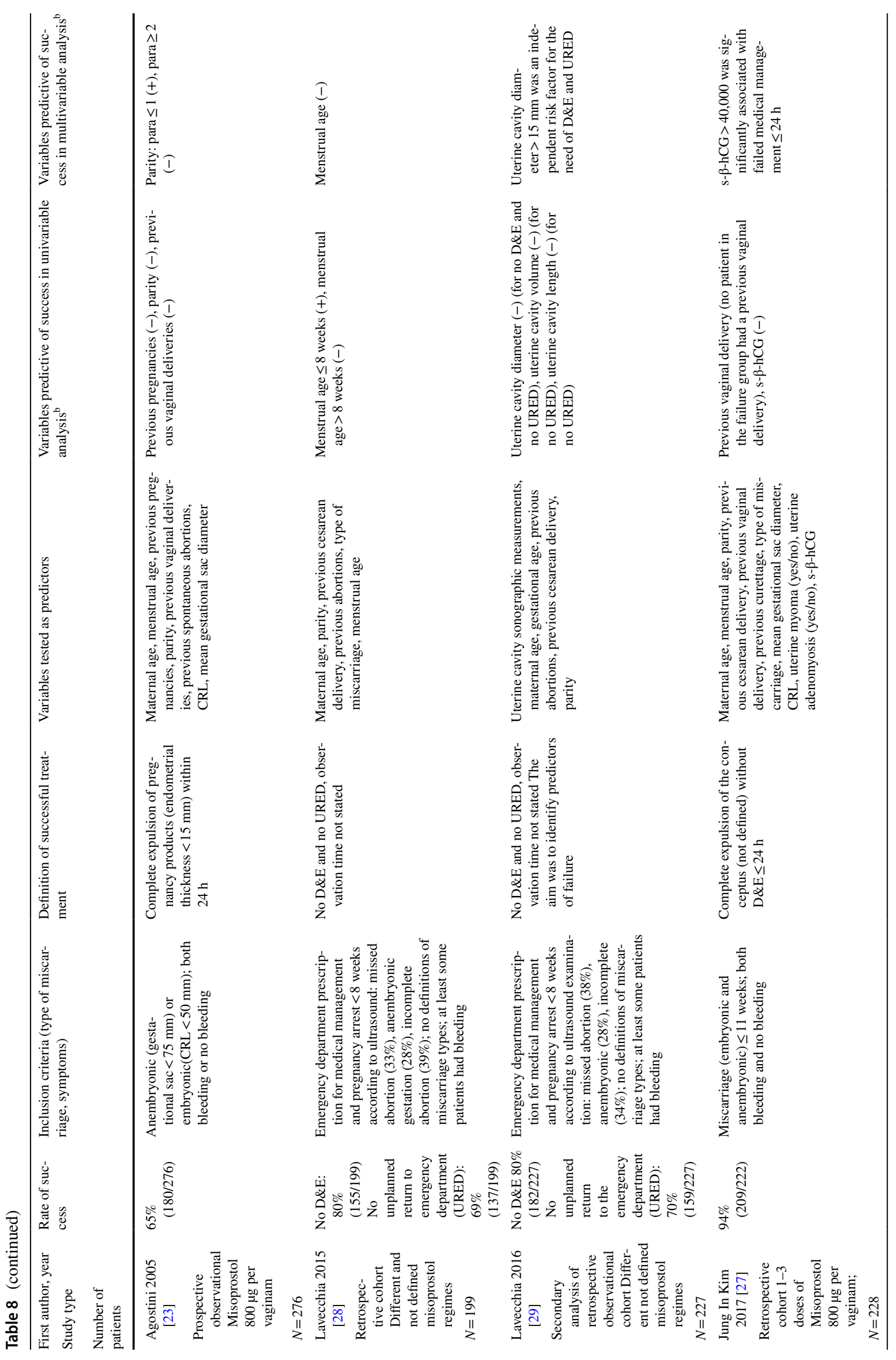




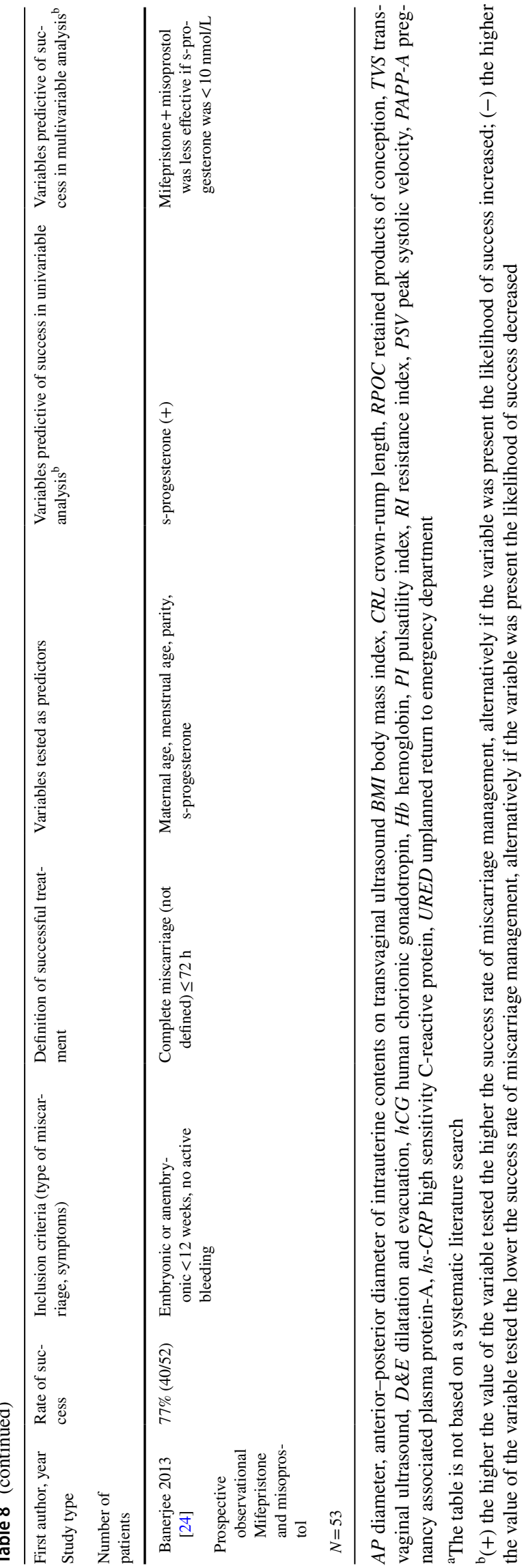

probably explained by differences in patient selection, definition of treatment success and predictor variables tested.

Some women prefer expectant management to medical intervention [17, 49] and knowledge about prognostic factors is important for being able to provide them with realistic expectations of treatment success. Our prediction models are helpful in this respect but need to be prospectively validated. A simple blood test predicting successful outcome without treatment would be clinically valuable and therefore a goal of future research. Serum-progesterone or serum-hCG results may not always be available at the time of patient counselling. Therefore, they may be less clinically useful as predictors than clinical and ultrasound information available bedside.

Acknowledgements Open access funding provided by Lund University. This study was funded by the Swedish state under the agreement between the Swedish government and the county councils, the ALFagreement, and by another Swedish governmental grant (Landstingsfinansierad Regional Forskning).

Author contributions AF: data collection, data analysis, manuscript writing/editing. LJ: data collection, data analysis, manuscript editing. PS: project development, data analysis, manuscript editing. LV: project development, data analysis, manuscript writing/editing.

Funding The study sponsors had no role in the collection, analysis or interpretation of data or in the writing of the manuscript.

\section{Compliance with ethical standards}

Conflict of interest None of the authors have any conflict of interest.

Ethical approval This study was performed in line with the principles of the Declaration of Helsinki. Approval was granted by the regional ethical review board, Lund University, Sweden (Dnr 83/2008).

Consent to participate Written and oral informed consent was obtained from all individual participants included in the study.

Open Access This article is licensed under a Creative Commons Attribution 4.0 International License, which permits use, sharing, adaptation, distribution and reproduction in any medium or format, as long as you give appropriate credit to the original author(s) and the source, provide a link to the Creative Commons licence, and indicate if changes were made. The images or other third party material in this article are included in the article's Creative Commons licence, unless indicated otherwise in a credit line to the material. If material is not included in the article's Creative Commons licence and your intended use is not permitted by statutory regulation or exceeds the permitted use, you will need to obtain permission directly from the copyright holder. To view a copy of this licence, visit http://creativecommons.org/licenses/by/4.0/.

\section{References}

1. Hemminki E (1998) Treatment of miscarriage: current practice and rationale. Obstet Gynecol 91:247-253 
2. Ellish NJ, Saboda K, O’Connor J, Nasca PC, Stanek EJ, Boyle C (1996) A prospective study of early pregnancy loss. Hum Reprod 11:406-412

3. Regan L, Braude PR, Trembath PL (1989) Influence of past reproductive performance on risk of spontaneous abortion. BMJ 299:541-545

4. Nielsen S, Hahlin M, Platz-Christensen J (1999) Randomised trial comparing expectant with medical management for first trimester miscarriages. BJOG 106:804-807

5. Trinder J, Brocklehurst P, Porter R, Read M, Vyas S, Smith L (2006) Management of miscarriage: expectant, medical, or surgical? Results of randomised controlled trial (miscarriage treatment (MIST) trial). BMJ 332:1235-1240

6. Fernlund A, Jokubkiene L, Sladkevicius P, Valentin L (2018) Misoprostol treatment vs expectant management in women with early non-viable pregnancy and vaginal bleeding: a pragmatic randomized controlled trial. Ultrasound Obstet Gynecol 51:24-32

7. Bagratee JS, Khullar V, Regan L, Moodley J, Kagoro H (2004) A randomized controlled trial comparing medical and expectant management of first trimester miscarriage. Hum Reprod 19:266-271

8. Blohm F, Fridén BE, Milsom I, Platz-Christensen JJ, Nielsen S (2005) A randomised double blind trial comparing misoprostol or placebo in the management of early miscarriage. BJOG 112:1090-1095

9. Wood SL, Brain PH (2002) Medical management of missed abortion: a randomized clinical trial. Obstet Gynecol 99:563-566

10. Lister MS, Shaffer LET, Bell JG, Lutter KQ, Moorma KH (2005) Randomized, double-blind, placebo-controlled trial of vaginal misoprostol for management of early pregnancy failures. Am J Obstet Gynecol 193:1338-1343

11. Kolte AM, Bernardi LA, Christiansen OB, Quenby S, Farquharson RG, Goddjin M, Stephenson MD (2015) Terminology for pregnancy loss prior to viability: a consensus statement from the ESHRE early pregnancy special interest group. Hum Reprod 30:495-498

12. Kim C, Barnard S, Neilson JP, Hickey M, Vazquez JC, Dou L (2017) Medical treatments for incomplete miscarriage. Cochrane Database Syst Rev 1:Cd07223

13. Jurkovic D, Ross JA, Nicolaides KH (1998) Expectant management of missed miscarriage. BJOG 105:670-671

14. Acharya G, Morgan H (2002) Does gestational sac volume predict the outcome of missed miscarriage managed expectantly? J Clin Ultrasound 30:526-531

15. Casikar I, Lu C, Reid S, Condous G (2013) Prediction of successful expectant management of first trimester miscarriage: development and validation of a new mathematical model. Aust N Z J Obstet Gynaecol 53:58-63

16. Elson J, Tailor A, Salim R, Hillaby K, Dew T, Jurkovic D (2005) Expectant management of miscarriage-prediction of outcome using ultrasound and novel biochemical markers. Hum Reprod 20:2330-2333

17. Luise C, Jermy K, May C, Costello G, Collins WP, Bourne TH (2002) Outcome of expectant management of spontaneous first trimester miscarriage: observational study. BMJ 324:873-875

18. Memtsa M, Jauniaux E, Gulbis B, Nyrhinen NC, Jurkovic D (2017) Maternal serum markers in predicting successful outcome in expectant management of missed miscarriage. Reprod Biomed Online 34:98-103

19. Nielsen S, Hahlin M, Odén A (1996) Using a logistic model to identify women with first-trimester spontaneous abortion suitable for expectant management. BJOG 103:1230-1235

20. Wieringa-de Waard M, Ankum WM, Bonsel GJ, Vos J, Biewenga P, Bindels PJ (2003) The natural course of spontaneous miscarriage: analysis of signs and symptoms in 188 expectantly managed women. Brit J Gen Practice 53:704-708
21. Schwarzler P, Holden D, Nielsen S, Hahlin M, Sladkevicius P, Bourne TH (1999) The conservative management of first trimester miscarriages and the use of colour Doppler sonography for patient selection. Hum Reprod 14:1341-1345

22. Casikar I, Lu C, Reid S, Condous G (2013) Does symptomatology at presentation correlate with successful expectant management of first trimester miscarriage: a prospective observational study. Aust N Z J Obstet Gynaecol 53:178-183

23. Agostini A, Ronda I, Capelle M, Romain F, Bretelle F, Blanc B (2005) Influence of clinical and ultrasound factors on the efficacy of misoprostol in first trimester pregnancy failure. Fertil Steril 84:1030-1032

24. Banerjee AK, Emembolu JO, Habiba M (2013) The association between serum progesterone and outcome of medical management of early fetal demise: a pilot study. J Obstet Gynaecol 33:384-386

25. Casikar I, Lu C, Oates J, Bignardi T, Alhamdan D, Condous G (2012) The use of power Doppler colour scoring to predict successful expectant management in women with an incomplete miscarriage. Hum Reprod 27:669-675

26. Creinin MD, Huang X, Westhoff C, Barnhart K, Gilles JM, Zhang J (2006) Factors related to successful misoprostol treatment for early pregnancy failure. Obstet Gynecol 107:901-907

27. Kim JI, Park IY, Yim JM, Cheon JY, Yun HG, Kwon JY (2017) Serum beta-hCG concentration is a predictive factor for successful early medical abortion with vaginal misoprostol within 24 hours. Obstet Gynecol Sci 60:427-432

28. Lavecchia M, Abenhaim HA (2015) Effect of menstrual age on failure of medical management in women with early pregnancy loss. J Obstet Gynaecol Can 37:617-623

29. Lavecchia M, Klam S, Abenhaim HA (2016) Effect of uterine cavity sonographic measurements on medical management failure in women with early pregnancy loss. J Ultrasound Med 35:1705-1710

30. Luise C, Jermy K, Collins WP, Bourne TH (2002) Expectant management of incomplete, spontaneous first-trimester miscarriage: outcome according to initial ultrasound criteria and value of follow-up visits. Ultrasound Obstet Gynecol 19:580-582

31. Odeh M, Tendler R, Kais M, Maximovsky O, Ophir E, Bornstein J (2010) Early pregnancy failure: factors affecting successful medical treatment. Isr Med Assoc J 12:325-328

32. Schreiber CA, Ratcliffe SJ, Quinley KE, Miller C, Sammel MD (2015) Serum biomarkers may help predict successful misoprostol management of early pregnancy failure. Reprod Biology 15:79-85

33. Abdallah Y, Daemen A, Guha S, Syed S, Naji O, Pexsters A et al (2011) Gestational sac and embryonic growth are not useful as criteria to define miscarriage: a multicenter observational study. Ultrasound Obstet Gynecol 38:503-509

34. Abdallah Y, Daemen A, Kirk E, Pexsters A, Naji O, Stalder C et al (2011) Limitations of current definitions of miscarriage using mean gestational sac diameter and crown-rump length measurements: a multicenter observational study. Ultrasound Obstet Gynecol 38:497-502

35. Jeve Y, Rana R, Bhide A, Thangaratinam S (2011) Accuracy of first-trimester ultrasound in the diagnosis of early embryonic demise: a systematic review. Ultrasound Obstet Gynecol 38:489-496

36. Levi CS, Lyons EA, Lindsay DJ (1990) Ultrasound in the first trimester of pregnancy. Radiol Clin North Am 28:19-38

37. National Guideline C: ACR Appropriateness Criteria ${ }^{\circledR}$ first trimester bleeding. https://www.guideline.gov/summaries/summa ry/43883. Accessed 24 Apr 2017

38. National Institute of care and excellence: ectopic pregnancy and miscarriage: diagnosis and initial management. https://www.nice. org.uk/guidance/cg154. Accessed 24 Apr 2017

39. Valentin L, Sladkevicius P, Laurini R, Soderberg H, Marsal $\mathrm{K}$ (1996) Uteroplacental and luteal circulation in normal 
first-trimester pregnancies: Doppler ultrasonographic and morphologic study. Am J Obstet Gynecol 174:768-775

40. Valentin L, Sladkevicius P, Laurini R, Soderberg H, Olofsson P, Marsal K (1995) Effect of a prostaglandin E1 analogue (gemeprost) on uterine and luteal circulation in normal first trimester pregnancies. A Doppler velocimetry study. Eur J Obstet Gynecol Reprod Biol 59:25-34

41. Practice Bulletin No (2015) 150: early pregnancy loss. Obstet Gynaecol 125:1258-1267

42. Australasian Society for Ultrasound in Medicine: guidelines for the performance of first trimester ultrasound. https://www.asum. com.au/files/public/SoP/D11-Guidelines-for-the-Performance-ofFirst-Trimester-Ultrasound.pdf. Accessed 22 Aug 2017

43. Morin L, Cargill YM, Glanc P (2016) Ultrasound Evaluation of First Trimester Complications of Pregnancy. J Obstet Gynaecol Can 38:982-988

44. Nielsen S, Hahlin M (1995) Expectant management of first-trimester spontaneous abortion. Lancet 345:84-86

45. Chen BA, Creinin MD (2008) Medical management of early pregnancy failure: efficacy. Semin Reprod Med 26:411-422
46. Creinin MD, Harwood B, Guido RS, Fox MC, Zhang J (2004) Endometrial thickness after misoprostol use for early pregnancy failure. Int J Gynaecol Obstet 86:22-26

47. Reeves MF, Lohr PA, Harwood BJ, Creinin MD (2008) Ultrasonographic endometrial thickness after medical and surgical management of early pregnancy failure. Obstet Gynecol 111:106-112

48. Sawyer E, Ofuasia E, Ofili-Yebovi D, Helmy S, Gonzalez J, Jurkovic D (2007) The value of measuring endometrial thickness and volume on transvaginal ultrasound scan for the diagnosis of incomplete miscarriage. Ultrasound Obstet Gynecol 29:205-209

49. Wieringa-de Waard M, Bindels PJ, Vos J, Bonsel GJ, Stalmeier PF, Ankum WM (2004) Patient preferences for expectant management vs. surgical evacuation in first-trimester uncomplicated miscarriage. J Clin Epidemiol 57:167-173

Publisher's Note Springer Nature remains neutral with regard to jurisdictional claims in published maps and institutional affiliations. 